\title{
Cesarean section rates in São Paulo State: regional inequalities in SUS obstetric care
}

\section{Fabiana Santos Lucena 1}

iD https://orcid.org/0000-0002-3928-1300

Mariana Tarricone Garcia 2

https://orcid.org/0000-0001-5124-8936

Lígia Schiavon Duarte 3

https://orcid.org/0000-0001-5822-9033

1 Núcleo de Formação e Desenvolvimento Profissional. Instituto de Saúde. São Paulo, SP, Brasil.

2,3 Núcleo de Serviços e Sistemas de Saúde. Instituto de Saúde. Rua Santo Antônio, 590. 5 andar. São Paulo, SP, Brasil. CEP: 01.314-000.

E-mail: marianatarricone@gmail.com

\begin{abstract}
Objectives: to analyze the relation between cesarean section rates in SUS childbirth care establishments in São Paulo State and urbanization conditions, according to Robson group classification system.

Methods: Sistema de Informação sobre Nascidos Vivos (Live Births Information System) and Cadastro Nacional de Estabelecimentos de Saúde (National Registry of Health Establishments) 2016 databases were analyzed. The studied outcome was cesarean section rates in the establishments, grouped by administration type (public or nonprofit entities) and urbanization condition.

Results: the cesarean section rate in SUS childbirth care establishments was $50.5 \%$, ranging from $41.1 \%$ in metropolitan regions up to $75.2 \%$ in the low urbanized regions. Cesarean section rates in public administration establishments (38.2\%) were significantly lower than the nonprofit administration maternity hospitals (62.3\%). Robson groups 5 and 2 contributed mostly to the cesarean section global rate (36.6\% and $21.5 \%$, respectively).

Conclusions: The less urbanized regions showed significantly higher cesarean section rates than the metropolitan and highly urbanized regions. Cesarean section rates of public administration establishments were significantly lower than the nonprofit administration establishments. However, when separated by urbanization condition its difference was only observed in the metropolitan regions.
\end{abstract}

Key words Cesarean section, Childbirth, Regionalization, Urbanization, Public health system

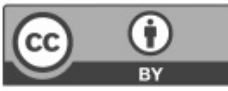




\section{Introduction}

Cesarean sections have escalated worldwide in the last decades, despite the lack of evidence to support substantial maternal and perinatal benefits. ${ }^{1}$ Brazil is known worldwide for the high cesarean section rates (CSR), which continue to rise steadily in all the regions in the country, becoming the main birth route since 2009. ${ }^{2}$ Public services also deserve attention despite its greater frequency in private services. In 2014, the cesarean section rate in SUS (Public Health Service) in São Paulo State was $43.5 \%$, with an increase of $7.7 \%$ in relation to $2010 .^{3}$

In Brazil, public policies aimed to change childbirth care but have not shown satisfactory results, and maternal morbidity and mortality rates remain high and stable, besides the constant increase in cesarean sections and prematurity. 4 A slight reduction in maternal mortality was observed in São Paulo State in early 2000's, reaching 37 maternal deaths/100 thousand live births in 2012 , followed by a sharp increase, reaching 51 maternal deaths/100 thousand live births in 2016.5 Initiatives were announced to improve childbirth and birth care in the state and ensure the right to humanized childbirth in $100 \%$ of the public health establishments within São Paulo State, as provided by the Resolution SS 42/2015. The construction of Planos Institucionais de Humanização (Institutional Humanization Plans) was also encouraged in the units participating in the Politica Estadual de Humanização (PEH) (State Humanization Policy), both present in the 20162019 Plano Estadual de Saúde (State Health Plan).

In an attempt to reduce cesarean section rates, WHO proposed that the Robson classification (RC) should be used as a standard instrument in different countries to assess, monitor, and compare cesarean section rates over time, in the same hospital and among different hospitals. ${ }^{6}$ Also, the classification can characterize the type of population served in the analysis of obstetric care and the modification of practices to adapt the cesarean section rates in specific groups, aiming for better maternal and perinatal outcomes. ${ }^{7}$

It is also worth mentioning that understanding cesarean section rates require in considering childbirth care model in different locations. According to Patah and Malik, ${ }^{8}$ childbirth care model is an important explanatory factor for the type of childbirth outcome. The authors stress the complex and conflicting relation between service providers, physicians, and patients, especially in the Brazilian metropolitan regions and the large urban centers, where greater participation of civil society move- ments in expanding citizenship is observed. ${ }^{8}$ The profound regional inequalities in the national territory, especially in the access to health services, concern not only the large Brazilian regions and their federative units, but, above all, the enormous concentration of investments, goods, and services in privileged urban centers. ${ }^{9}$ This aspect gains even more relevance when considering São Paulo State and its heterogeneous urban network. ${ }^{10}$ It is worth complementing that the greater supply of human and technological resources and health equipment in more densely urbanized regions, such as metropolitan region and the large urban centers, can make up different childbirth care models than those in regions of lower urban density.

This paper aims to analyze the relation between cesarean section rates according to Robson's classification groups of establishments that provide childbirth care in SUS (Public Health Service) in São Paulo and the urbanization conditions of these establishments are located.

\section{Methods}

Data from the Sistema de Informações sobre Nascidos Vivos (Sinasc) (Live Birth Information System) managed by the Ministry of Health and available online at the Departamento de Informática do SUS (Datasus) (Informatic Department), for live births in São Paulo State in 2016 were analyzed. The cesarean section rates for each group of Robson Classification by health establishments where births occurred were retrieved from the live birth monitoring panel according to the epidemiological risk classification (Robson Groups) from the Departamento de Informação e Análise Epidemiológica da Secretaria de Vigilância em Saúde do Ministério da Saúde (Information Department and Epidemiological Analysis of the Health Surveillance Secretary of the Ministry of Health).

Groups 1 to 5 of Robson Classification were prioritized for this study, which refers to single pregnancies, fetuses in cephalic presentation and at term. These groups concentrated $85.1 \%$ of all live births in São Paulo State in 2016, and the expectation was to have lower cesarean rates than groups 6 to 10 . Groups 1 and 2 included nulliparous women, whereas spontaneous labor (SL) occurred in group 1, and SL did not occur or was induced in group 2. Groups 3 and 4 included multiparous women without a previous cesarean section, where SL occurred in group 3, and SL did not occur or was induced in group 4 . Group 5 refers to multiparous 
women with a previous cesarean section.

Based on information from the Cadastro Nacional de Estabelecimentos de Saúde (CNES), (National Registry of Health Establishments), all establishments listed as "Business Entities" in the "Legal Nature" field, that is, private establishments, were excluded. Only establishments that provided services for SUS were included: those described as "Public Administration" and "Nonprofit Entities". Among the establishments classified as "Nonprofit Entities", those that did not offer obstetric beds for SUS were excluded.

The studied outcome was the cesarean rates of the establishments where births occurred. The establishments were grouped by the type of administration service (public or by philanthropic entities) and by health regions according to their urbanization condition (metropolitan, high urbanization, medium urbanization, and low urbanization), as proposed by Duarte. 11

The inclusion in the analysis of health regions characterized by their urbanization condition was motivated by the need to consider the regional differences where the establishments studied are located São Paulo State presents territorial heterogeneities related, among other things, to population concentration, economic activity, and supply of resources, which must be considered when formulating public policies

The urban network represents the territorial synthesis of the multiple processes deriving from a given social organization and a determined productive space. For this reason, the typology proposed by Duarte, 11 based on the studies on Regiões de Influência das Cidades (REGIC) 10 (Cities Regions of Influence) and the urban network and regionalization of São Paulo State, was used in this study. 12 From these studies, Duarte classifies 645 cities in São Paulo State into seven types, namely11:

1) metropolitan city - is part of the metropolitan region, but not considered the main urban core in the region;

2) metropolitan center - is part of the metropolitan region and is considered the main urban core of the region;

3) city of an urban cluster - makes up of the urban cluster, but its centrality does not stand out in functioning as an urban cluster as a whole;

4) urban cluster center - makes up the urban cluster and stands out for its relevance in the centrality of its urban core;

5) isolated regional center - is not part of an urban cluster, whether metropolitan or not, and is relevant in the centrality of the urban core;
6) small regional center - is not part of an urban cluster, whether metropolitan or not, and the centrality of its urban core is of low intensity; and 7) local centers - the centrality of their urban centers serves only the limits of their territory.

Based on this typology of São Paulo cities, it is possible to characterize the 63 health regions (HR) into four categories of urbanization conditions:

- Low urbanization HR: formed only by cities classified as Local Centers, that is, without cities that make up the upper stratum of the urban network, or are composed of cities classified as Small Regional Centers. Twenty HRs were identified in this category.

- Medium Urbanization HR: composed of Isolated Regional Centers, besides the Local Centers and the HRs composed of Isolated Regional Centers, Local Centers, and cities classified as Small Regional Centers. 16 HRs were identified in this category.

- High urbanization HR: the 19 HRs with cities classified as Urban Cluster and or Urban Cluster Center were added. In other words, these HRs have several compositions that can also count on the presence of cities in the category of Local Centers and Small Regional Centers besides these cities.

- Metropolitan HRs: all HRs that coincide or are included in the selected formal Metropolitan Regions of São Paulo State. It is worth mentioning that São Paulo, Baixada Santista, and Metropolitana de Campinas house the Metropolitan Center. The others, which are located around the cities of São Paulo, do not have cities that stand out for their polarization. Eight HRs were identified in this category.

The Mann-Whitney U test was used to compare cesarean section rates by the type of administration of the establishments where the births occurred (direct public administration or administration by nonprofit entities). The Kruskal-Wallis test was used to compare cesarean section rates by location of the establishments where births occurred (metropolitan areas, high, medium, and low urbanization). All statistical analyses were performed using Stata Station version 13.0, TX, USA 2013. Statistical significance for all analyses was defined by a value of $p<0.05$.

\section{Results}

Table 1 shows the characteristics of the HRs by urbanization condition. Most of the population is found in the metropolitan regions (58.5\%), as has the largest share of State GDP (66.2\%). In 2016, the 339 health establishments providing childbirth care for 
SUS in São Paulo registered 428,817 live births, $49 \%$ of which occurred in 112 public administration establishments, and $51 \%$ in 227 establishments managed by nonprofit entities. Noteworthy is that $81 \%$ of the public administration establishments are located in the metropolitan or high urbanization regions $(\mathrm{n}=91)$. The opposite is true concerning establishments managed by nonprofit entities. That is, most are concentrated in less urbanized regions. All HRs in the State $(n=63)$ have establishments providing childbirth care for SUS, whether public administration or administered by nonprofit entities. However, public administration establishments are more concentrated in more urbanized regions, with all the metropolitan regions having at least one establishment $(\mathrm{n}=8)$. In low urbanization regions, this number drops to $30 \%(n=6)$. It is also important to note that the ratio of physicians per 1,000 inhabitants decreases according to the urbanization condition, which also occurs with the ratio of obstetric nurses by the establishment providing childbirth care. In 2016, 80\% of obstetric nurses working in SUS in São Paulo State were concentrated in the metropolitan regions.

According to Cadastro Nacional de Estabelecimentos de Saúde (CNES), (National Registry of Health Establishments) data, nonprofit entities allocate an average of $63.4 \%$ of obstetric beds for SUS. A total of 134 of the 227 establishments managed by nonprofit entities were Santa Casas (religious brotherhoods providing hospital care) (data not shown in tables).

Figure 1 shows that the percentage of live births in public administration establishments declines

\section{Table 1}

Socioeconomic, demographic, and health access characteristics according to urbanization conditions in health regions. São Paulo State, 2016.

\begin{tabular}{|c|c|c|c|c|c|}
\hline & Total & Metropolitan & High urbanization & Medium urbanization & Low urbanization \\
\hline \multicolumn{6}{|l|}{ Population 2016* } \\
\hline$N(\%)$ & $43.359 .005(100.0)$ & $25.381 .216(58.5)$ & $10.256 .412(23.7)$ & $5.078 .538(11.7)$ & $2.642 .839(6.1)$ \\
\hline \multicolumn{6}{|l|}{ GDP* } \\
\hline$\%$ of state GDP & 100,0 & 66,2 & 21,9 & 7,6 & 4.3 \\
\hline Per capita ( $\mathrm{R} \$)$ & $46,991.4$ & $53,177.0$ & $43,505.6$ & $30,348.5$ & $33,096.6$ \\
\hline \multicolumn{6}{|l|}{ Live births } \\
\hline \multicolumn{6}{|l|}{ N (\%) } \\
\hline Total & $428,817(100.0)$ & $247,722(57.8)$ & $99,505(23.2)$ & $56,000(13.0)$ & $25,590(6.0)$ \\
\hline Public administration & $210,012(100.0)$ & $172,139(82.0)$ & $24,303(11.6)$ & $11,553(5.5)$ & $2,017(1.0)$ \\
\hline Nonprofit entities & $218,805(100.0)$ & $75,583(34.5)$ & $75,202(34.4)$ & $44,447(20.3)$ & $23,573(10.8)$ \\
\hline \multicolumn{6}{|l|}{ N Establishments } \\
\hline \multicolumn{6}{|l|}{$\mathrm{N}(\%)$} \\
\hline Total & $339(100.0)$ & $103(30.4)$ & $100(29.5)$ & $76(22.4)$ & $60(17.7)$ \\
\hline Public administration & $112(100.0)$ & $71(63.4)$ & $20(17.9)$ & $14(12.5)$ & $7(6.3)$ \\
\hline Nonprofit entities & $227(100.0)$ & $32(14.4)$ & $80(35.5)$ & $62(27.3)$ & $53(23.3)$ \\
\hline \multicolumn{6}{|l|}{$\mathrm{N}$ Health regions with } \\
\hline \multicolumn{6}{|l|}{ establishment } \\
\hline Total & 63 & 8 & 19 & 16 & 20 \\
\hline Public administration & 37 & 8 & 12 & 11 & 6 \\
\hline Nonprofit entities & 59 & 6 & 18 & 16 & 19 \\
\hline Physicians $/ 1,000$ inhabitants** & 2.4 & 2.7 & 2.2 & 2.0 & 1.6 \\
\hline \multicolumn{6}{|l|}{ Obstetric nurses** } \\
\hline N/Establishment & 1.1 & 2.8 & 0.4 & 0.2 & 0.3 \\
\hline \multicolumn{6}{|l|}{ N Establishments with } \\
\hline Obstetric nurses & 44 & 26 & 9 & 4 & 5 \\
\hline
\end{tabular}

Source: *SEADE Foundation; **National Registry of Health Establishments (Cadastro Nacional de Estabelecimentos de Saúde - CNES). 
sharply with the level of urbanization, from $69.5 \%$ in the metropolitan regions to $7.9 \%$ in low urbanized regions. Regarding the presence of establishments managed by nonprofit entities, the percentage increases with lower urbanization, $31.1 \%$ in the metropolitan regions and $88.3 \%$ in low urbanized regions.

In Figure 2, when analyzing the establishments according to the urban network, in general, the less urbanized the area, the higher is the cesarean section rates, with statistically significant differences regarding the set of live births, and groups 1 to 5 of Robson Classification, both in public administration establishments and those administered by nonprofit entities. Concerning public administration establishments, group 1 had the highest cesarean section rates in the medium urbanization regions (52.1\%). Group 2 had the highest rate in regions with low urbanization $(79.7 \%)$. The highest cesarean section rates in group 3 was recorded in the medium urbanization regions $(18.4 \%)$. In group 4, the highest cesarean section rates was in low urbanized regions (44.7\%). Finally, group 5 had the highest cesarean section rates in the regions with low urbanization $(88.2 \%)$. In all groups, the lowest cesarean section rates are found in the metropolitan regions. When births are observed in establishments administered by nonprofit entities, the low urbanized regions had the highest cesarean section rates in all groups, with $72.5 \%$ in group $1,83.7 \%$ in group $2,35.9 \%$ in group $3,58.0 \%$ in group 4 , and $93.6 \%$ in group 5 . Noteworthy is that the lowest cesarean section rates in these establishments are higher than the lowest rates in the public administration establishments for groups 1,3 , and 4 .

Table 2 shows that the differences between the cesarean section rates of establishments according to the type of administration (public or nonprofit) are statistically significant in only some categories of urbanization condition. When looking at all the

\section{Figure 1}

Distribution of live births and places of birth according to the type of administration and urbanization conditions in the health regions. São Paulo State, 2016.
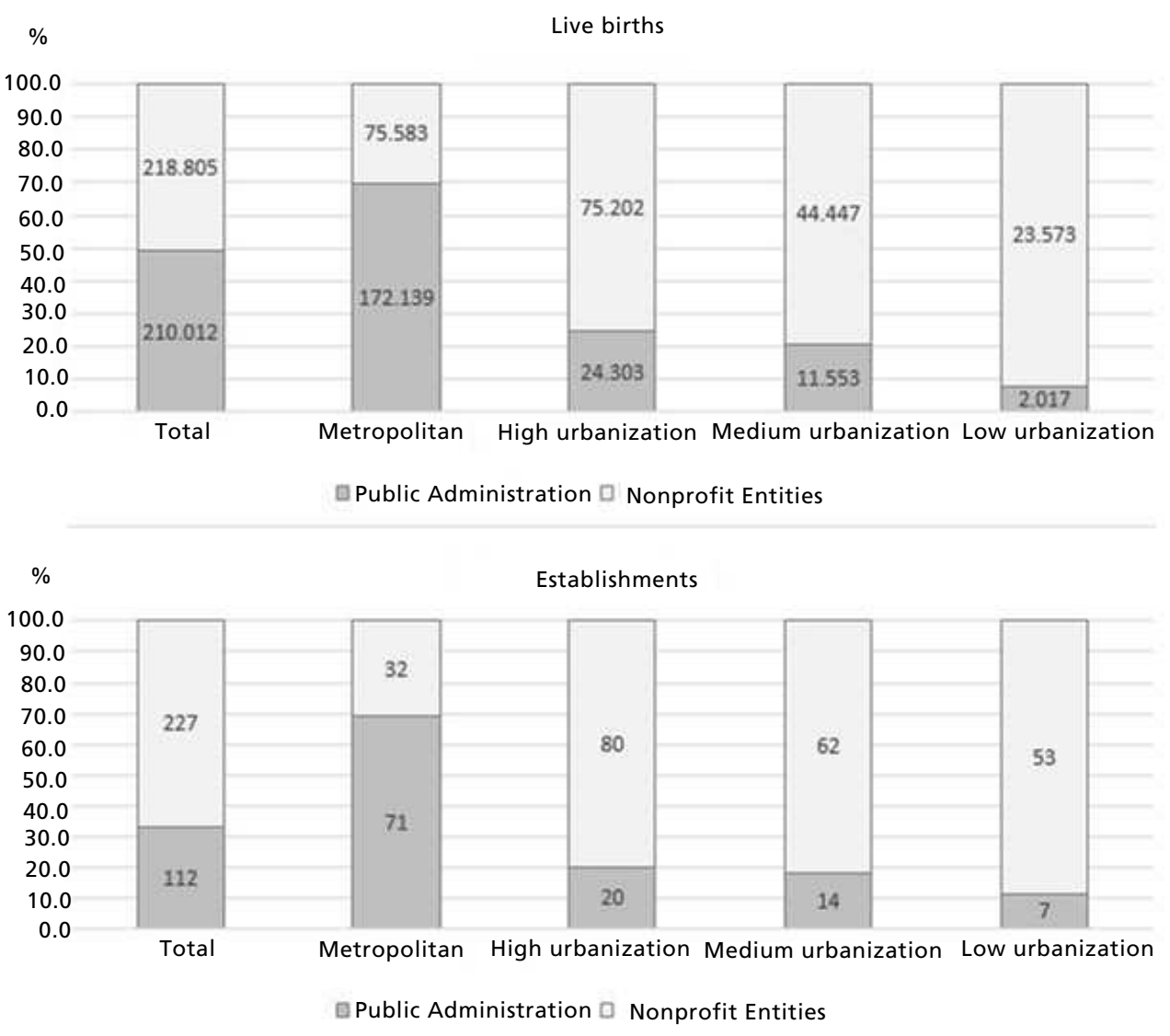
health regions, without differentiating them by urbanization condition, the cesarean section rates of the public administration establishments are significantly lower than those establishments managed by nonprofit entities, both concerning the total number of live births and groups 1 to 5 . This difference is maintained in the metropolitan regions for the total number of births and groups 1 to 5. In high urbanization regions, only the cesarean section rates of establishments administered by nonprofit entities referring to group 1 are significantly higher than those of the public establishments. The rates do not differ significantly in the medium and low urbanization regions. Noteworthy is the cesarean section rate in nulliparous women with spontaneous labor of $72.5 \%$ in establishments managed by nonprofit entities located in low urbanized regions.

Table 3 shows the relative contribution of groups 1 to 5 of Robson Classification in the overall cesarean section rates. Regarding all establishments, groups 1,2 , and 5 concentrate $68.8 \%$ of all cesarean sections performed. Another relevant issue refers to

Figure 2

Cesarean section rates of public administration establishments and nonprofit entities according to Robson groups and the urbanization conditions in the health regions. São Paulo State, 2016.
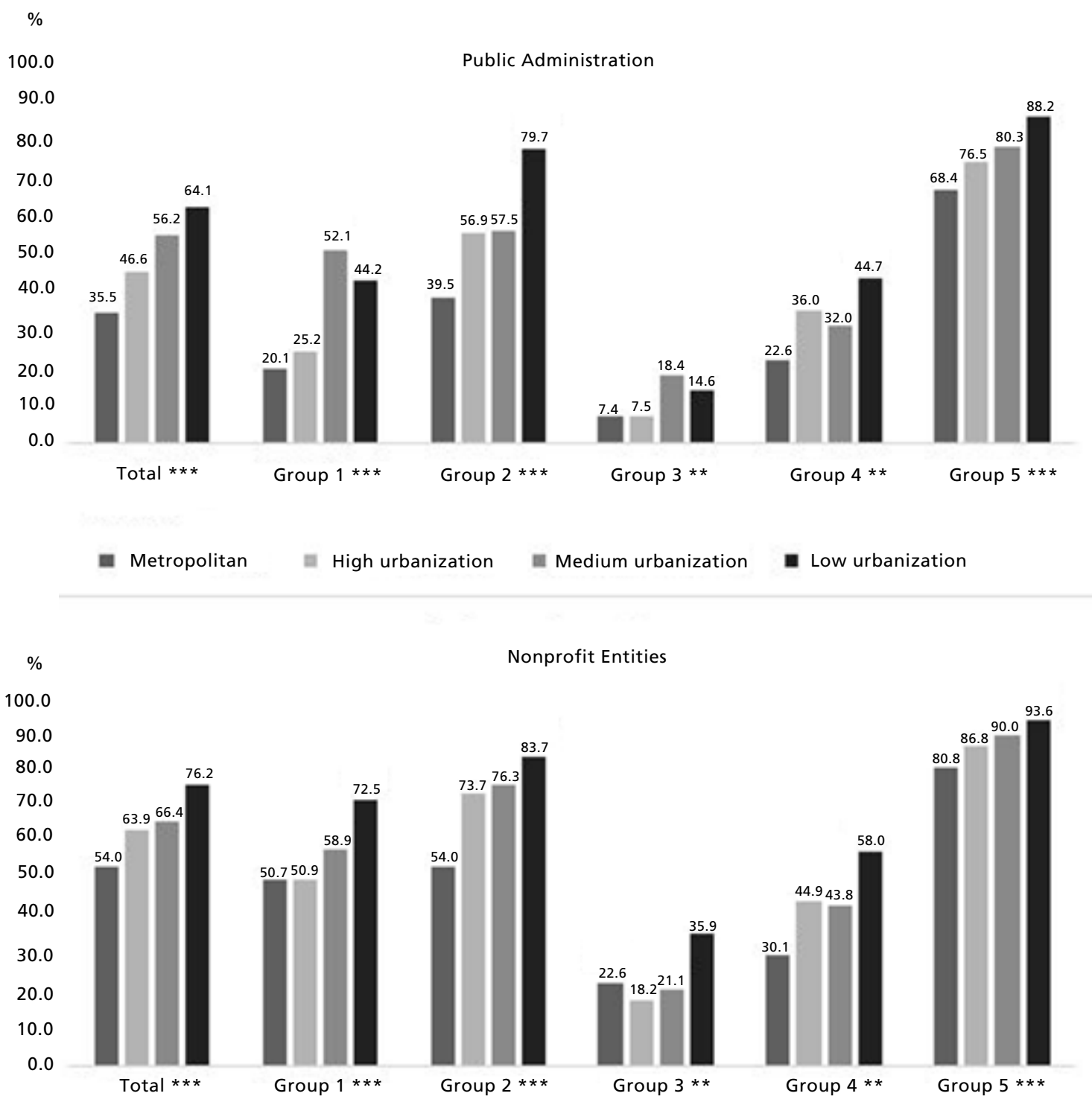

$* * p<0.01 ; * * * p<0.001$ 
the proportion of women going into labor. Among the primiparous women (groups 1 and 2), only $42.1 \%$ go into labor spontaneously $(n=59,734)$, and the proportion is $53.4 \%(n=66,166)$ among the multiparous women with a normal childbirth (groups 3 and 4). The relative contributions of groups 1 and 2 in the global cesarean section rates are significantly higher in the establishments managed by philanthropic entities $(p<0.05$ and $p<0.01$, respectively) when these establishments are divided by the type of administration. When establishments are analyzed separately by urban network, the relative contribution of group 2 is noted that establishments managed by nonprofit entities in the metropolitan regions is significantly higher than in the public administration establishments $(p<0.01)$. The relative contributions do not differ significantly in high, medium, and low urbanization regions.

\section{Discussion}

This is the first study that compared the cesarean section rates of establishments that provide childbirth care in SUS according to health regions with different urbanization conditions in São Paulo State.

The study found that, in São Paulo State, $51 \%$ of live births occurred in establishments managed by nonprofit entities. In the medium and low urbanization regions, these proportions were $79.4 \%$ and $92.1 \%$ of live births, respectively. The percentage of live births was higher in public establishments $(69.5 \%)$ only in the health regions classified as metropolitan. In other words, most births occurred in the nonprofit entities in less urbanized regions, reflecting the offering of this type of establishment in these regions.

An important finding in this study refers to the differences between cesarean section rates in public and philanthropic entities. The difference between these rates is apparent in the metropolitan regions, and the public establishments show the lowest cesarean section rates. Such gaps cease to be significant as the less urbanized regions are analyzed, that is, the cesarean section rates in public establishments are similar to the rates of the nonprofit establishments, besides being relatively high, similar to the rates of the Brazilian private establishments. 13 Zaiden et al. ${ }^{14}$ found that cesarean sections are more likely to be performed in establishments located outside the capitals and the establishments that do not exclusively attend SUS (mixed hospitals). While there are limitations on the comparative purposes, since the authors do not differentiate urbanization condition of the cities that are not capitals, we can say that the results are in line with the findings of this study.

When data are analyzed according to the urban network in the nonprofit establishments, the cesarean rates are higher in the low urbanization regions in all Robson Groups analyzed in this study (G1 to G5). When data on public establishments were analyzed, a higher rate of cesarean sections was observed in groups that included women who spontaneously entered into labor (G1 and G3) in the medium urbanization regions. A higher rate of cesarean sections was noted in the groups that included women who did not go into labor (G2 and G4) and women who underwent previous cesarean section (G5) in low urbanized regions. The lowest cesarean section rates occurred in the metropolitan regions in all Robson Classification groups.

Regarding the performance of cesarean sections in women who did not go into labor spontaneously, Zaiden et al.14 observed the influence of hospital characteristics on the likelihood of undergoing elective cesarean section in the Southeast region of the country. Among women with SUS-financed childbirth, the authors identified a higher prevalence of this procedure in private hospitals that receive public and private funding (mixed hospitals), outside the capitals, and with a lower annual volume of childbirths. The authors hypothesize that the type of care provided to SUS patients in mixed hospitals suffers from a type of "contamination" in organizing private hospitals, increasing the prevalence of cesarean sections in women before going into labor spontaneously. Alonso et al. 15 also observed that although several factors (socioeconomic, demographic, clinical, and among others) are associated with higher cesarean section rates in the Southeast region, the most significant one was referred to the private financing source in the care received.

A disturbing finding in this study was, contrary to the expectations, less than half $(42.1 \%)$ of the nulliparous women with a single, full-term, cephalic fetus went into labor spontaneously (Group 1). This situation is suggestive of a vicious cycle in which nulliparous women receive care that does not allow them to go into labor spontaneously and are subjected to interventions that result in high cesarean section rates in group 1, which was $39.0 \%$, contrasting studies from other countries, such as the Netherlands, where group 1 showed a cesarean section rate of $9.6 \% 13$, and in the United States, where this rate was $14.8 \% .16$ In this study, cesarean section rates in nulliparous women with a single pregnancy and fetus in cephalic presentation (groups 1 and 2) was $49.3 \%$, which was higher than the 
Table 2

Cesarean rates of establishments according to the type of administration, Robson groups, and urbanization conditions in the health regions. São Paulo State, 2016.

\begin{tabular}{|c|c|c|c|c|c|c|}
\hline \multirow{2}{*}{$\begin{array}{l}\text { Urbanization conditio } \\
\text { categories }\end{array}$} & \multicolumn{2}{|c|}{ Total } & \multicolumn{2}{|c|}{ Public Administration } & \multicolumn{2}{|c|}{ Nonprofit entities } \\
\hline & N Establishments & $\begin{array}{c}\text { Cesarean section } \\
\text { rate }\end{array}$ & N Establishments & $\begin{array}{c}\text { Cesarean section } \\
\text { rate }\end{array}$ & N Establishments & $\begin{array}{c}\text { Cesarean section } \\
\text { rate }\end{array}$ \\
\hline \multicolumn{7}{|l|}{ Total } \\
\hline Total number of live births & 339 & 50.5 & 112 & 38.2 & 227 & $62.3 * * *$ \\
\hline Group 1 & 326 & 39.0 & 107 & 22.5 & 219 & $55.1 * * *$ \\
\hline Group 2 & 324 & 56.8 & 108 & 43.0 & 216 & $68.2 * * *$ \\
\hline Group 3 & 327 & 13.5 & 107 & 7.9 & 220 & $22.2 * * *$ \\
\hline Group 4 & 326 & 31.6 & 108 & 24.6 & 218 & $39.6 * * *$ \\
\hline Group 5 & 335 & 79.6 & 111 & 70.6 & 224 & $86.5 * * *$ \\
\hline \multicolumn{7}{|l|}{ Metropolitan } \\
\hline Total number of live births & 103 & 41.1 & 71 & 35.5 & 32 & $54.0 * * *$ \\
\hline Group 1 & 102 & 29.5 & 70 & 20.1 & 32 & $50.7 * * *$ \\
\hline Group 2 & 102 & 44.5 & 70 & 39.5 & 32 & $54.0 * * *$ \\
\hline Group 3 & 101 & 10.7 & 70 & 7.4 & 31 & $22.6 * * *$ \\
\hline Group 4 & 102 & 24.9 & 70 & 22.6 & 32 & $30.1 * *$ \\
\hline Group 5 & 102 & 72.6 & 70 & 68.4 & 32 & $80.8 * * *$ \\
\hline \multicolumn{7}{|l|}{ High urbanization } \\
\hline Total number of live births & 100 & 59.6 & 20 & 46.6 & 80 & 63.9 \\
\hline Group 1 & 94 & 44.5 & 17 & 25.2 & 77 & $50.9 * *$ \\
\hline Group 2 & 94 & 70.1 & 18 & 56.9 & 76 & 73.7 \\
\hline Group 3 & 95 & 14.7 & 17 & 7.5 & 78 & 18.2 \\
\hline Group 4 & 95 & 42.5 & 18 & 36.0 & 77 & 44.9 \\
\hline Group 5 & 99 & 84.5 & 20 & 76.5 & 79 & 86.8 \\
\hline \multicolumn{7}{|l|}{ Medium urbanization } \\
\hline Total number of live births & 76 & 64.3 & 14 & 56.2 & 62 & 66.4 \\
\hline Group 1 & 73 & 57.6 & 13 & 52.1 & 60 & 58.9 \\
\hline Group 2 & 72 & 72.9 & 13 & 57.5 & 59 & 76.3 \\
\hline Group 3 & 74 & 20.5 & 14 & 18.4 & 60 & 21.1 \\
\hline Group 4 & 73 & 41.3 & 13 & 32.0 & 60 & 43.8 \\
\hline Group 5 & 75 & 88.2 & 14 & 80.3 & 61 & 90.0 \\
\hline \multicolumn{7}{|l|}{ Low urbanization } \\
\hline Total number of live births & 60 & 75.2 & 7 & 64.1 & 53 & 76.2 \\
\hline Group 1 & 57 & 70.4 & 7 & 44.2 & 50 & 72.5 \\
\hline Group 2 & 56 & 83.3 & 7 & 79.7 & 49 & 83.7 \\
\hline Group 3 & 57 & 33.9 & 6 & 14.6 & 51 & 35.9 \\
\hline Group 4 & 56 & 56.9 & 7 & 44.7 & 49 & 58.0 \\
\hline Group 5 & 59 & 93.2 & 7 & 88.2 & 52 & 93.6 \\
\hline
\end{tabular}

$* * p<0.01 ; * * * p<0.001$ 
Table 3

Relative contribution to the overall cesarean rate of establishments according to the type of administration, Robson groups, and urbanization conditions in the health regions. São Paulo State, 2016.

\begin{tabular}{|c|c|c|c|c|c|c|c|c|c|}
\hline \multirow{2}{*}{$\begin{array}{l}\text { Urbanization condition } \\
\text { categories }\end{array}$} & \multicolumn{3}{|c|}{ Cesarean section $(\mathrm{N})$} & \multicolumn{2}{|c|}{ Live births $(\mathrm{N})$} & \multicolumn{4}{|c|}{ Relative contribution (\%) in the overall cesarean section rate } \\
\hline & Total & Public Adm. & Nonprofit entities & Total & Public Adm. & Nonprofit entities & Total & Public Adm. & Nonprofit entities \\
\hline \multicolumn{10}{|l|}{ Total } \\
\hline Group 1 & 23288 & 6635 & 16653 & 59734 & 29523 & 30211 & 10.8 & 8.3 & $12.2^{*}$ \\
\hline Group 2 & 46598 & 15863 & 30735 & 81971 & 36909 & 45062 & 21.5 & 19.8 & $22.6 * *$ \\
\hline Group 3 & 8913 & 3173 & 5740 & 66166 & 40285 & 25881 & 4.1 & 4.0 & 4.2 \\
\hline Group 4 & 18235 & 7466 & 10769 & 57623 & 30398 & 27225 & 8.4 & 9.3 & 7.9 \\
\hline Group 5 & 79242 & 30293 & 48949 & 99509 & 33517 & 56584 & 36.6 & 37.8 & 35.9 \\
\hline \multicolumn{10}{|l|}{ Metropolitan } \\
\hline Group 1 & 10466 & 4954 & 5512 & 35489 & 24619 & 10870 & 10.3 & 8.1 & 13.5 \\
\hline Group 2 & 20535 & 11926 & 8609 & 46140 & 30187 & 15953 & 20.1 & 19.5 & 21.1 ** \\
\hline Group 3 & 4705 & 2560 & 2145 & 44005 & 34501 & 9504 & 4.6 & 4.2 & 5.3 \\
\hline Group 4 & 9171 & 5779 & 3392 & 36875 & 25603 & 11272 & 9.0 & 9.5 & 8.3 \\
\hline Group 5 & 36971 & 22916 & 14055 & 50914 & 33517 & 17397 & 36.3 & 37.5 & 34.5 \\
\hline \multicolumn{10}{|l|}{ High urbanization } \\
\hline Group 1 & 5668 & 793 & 4875 & 12737 & 3153 & 9584 & 9.6 & 7.0 & 10.1 \\
\hline Group 2 & 13999 & 2421 & 11578 & 19968 & 4257 & 15711 & 23.6 & 21.4 & 24.1 \\
\hline Group 3 & 1816 & 302 & 1514 & 12381 & 4041 & 8340 & 3.1 & 2.7 & 3.2 \\
\hline Group 4 & 5014 & 1153 & 3861 & 11810 & 3202 & 8608 & 8.4 & 10.2 & 8.0 \\
\hline Group 5 & 21956 & 4529 & 17427 & 25997 & 5923 & 20074 & 37.0 & 40.0 & 36.3 \\
\hline \multicolumn{10}{|l|}{ Medium urbanization } \\
\hline Group 1 & 4262 & 754 & 3508 & 7400 & 1448 & 5952 & 11.8 & 11.6 & 11.9 \\
\hline Group 2 & 8083 & 1163 & 6920 & 11086 & 2022 & 9064 & 22.5 & 17.9 & 23.5 \\
\hline Group 3 & 1418 & 271 & 1147 & 6904 & 1469 & 5435 & 3.9 & 4.2 & 3.9 \\
\hline Group 4 & 2738 & 449 & 2289 & 6632 & 1403 & 5229 & 7.6 & 6.9 & 7.8 \\
\hline Group 5 & 13061 & 2287 & 10774 & 14814 & 2849 & 11965 & 36.3 & 35.2 & 36.5 \\
\hline \multicolumn{10}{|l|}{ Low urbanization } \\
\hline Group 1 & 2892 & 134 & 2758 & 4108 & 303 & 3805 & 15.0 & 10.4 & 15.4 \\
\hline Group 2 & 3981 & 353 & 3628 & 4777 & 443 & 4334 & 20.7 & 27.3 & $20 ; 2$ \\
\hline Group 3 & 974 & 40 & 934 & 2876 & 274 & 2602 & 5.1 & 3.1 & 5.2 \\
\hline Group 4 & 1312 & 85 & 1227 & 2306 & 190 & 2116 & 6.8 & 6.6 & 6.8 \\
\hline Group 5 & 7254 & 561 & 6693 & 7784 & 636 & 7148 & 37.7 & 43.4 & 37.3 \\
\hline
\end{tabular}


national rate.

Dias et al. 17 found a cesarean section rate of $35.8 \%$ in nulliparous women with a single pregnancy and fetus in cephalic presentation assisted in the Brazilian public health services. Noteworthy is that group 2 (nulliparous women who did not go into labor spontaneously) were the second-largest relative contribution in the global cesarean section rate with $21.5 \%$ in São Paulo State, reaching $27.3 \%$ in public hospitals in the low urbanized region. Also noteworthy is the cesarean section rates of Group 1 in regions of low urbanization, where $70.4 \%$ of these women underwent cesarean section. This same group had a significantly lower cesarean section rate $(29.5 \%)$ in establishments in the metropolitan regions. In Uruguay, 18 no significant differences were found in cesarean section rates in group 1 between the countryside region $(24.8 \%)$ and capital $(22.7 \%)$, and these rates were similar to the rates found in this study in the metropolitan region.

As in other studies, cesarean section rates were close to $100 \%$ among women in group 5 of Robson Classification; that is, women with previous cesarean section. This group was also the most considerable relative contribution in overall cesarean section rates with $36.6 \%$ in São Paulo State, reaching $43.4 \%$ in the public hospitals in the low urbanized region, with no statistically significant differences between the public administration and the nonprofit establishments in different regions.

In a study on births in the Netherlands, group 5 accounted for $18.1 \%$ of the relative contribution to global cesarean section rates. 19 In the United States, group 5 contributed to $29.5 \%$ of all the cesarean sections performed. 16 Oliveira et al. 20 found an 11fold increase of a probable new cesarean section among women in group 5 residing in Maringá, Paraná State, assisted by SUS. Alonso et al. 15 found a 22-fold increase to likely in having another cesarean section among women assisted by SUS in the Southeast region.

The indication of a new cesarean section seems to be the most common practice, although there is no scientific evidence showing a significant increase in the risk of vaginal delivery among these women and of repeated surgery offering higher risk in future pregnancies. $20 \mathrm{~A}$ study conducted in Uruguay also shows a post-cesarean section culture, where $80.4 \%$ of the women underwent a new cesarean section ${ }^{21}$ in group 5. In the Netherlands, Zhang et al. ${ }^{19}$ showed that $75 \%$ of the women with previous cesarean section who went into labor successfully evolve into vaginal delivery, without observing increased risks of infant mortality or postpartum hemorrhage.
Although the experience in the Netherlands' cannot be reproduced in Brazil due to substantial differences in the care model, the magnitude of the disparity between the two countries regarding normal childbirth after the cesarean section suggests an essential field for future advances. After undergoing the first surgery, women in São Paulo are subjected to other cesarean sections. Thus, the care model produces cesarean section rate that tend to increase, requiring policies that can transform this logic, considering the different regional realities. Therefore, we can affirm that the lower the urbanization of the Health Regions, the higher the Cesarean Rates in all Robson Groups studied, showing a high number of potentially unnecessary cesareans in these women.

It is essential to analyze the data in São Paulo to advance the discussion on the regional differences found in this study. We can perceive a robust regional concentration when $58.5 \%$ of the population and $66.2 \%$ of the GDP are located in eight metropolitan Health Regions in São Paulo State. This state territorial concentration is reflected in the supply of health resources, including the number of physicians and obstetric nurses available. It is possible to observe that the medical density per thousand inhabitants in the set of the metropolitan Health Regions (ratio of 2.7) is higher than São Paulo State (ratio of 2.4). When analyzing the aggregation on urbanization conditions (high, medium, and low), the other Health Regions have a lower density than the State average, a ratio of 2.2, 2.0, and 1.6 , respectively. This inequality is also found when analyzing obstetric nurses' density by health establishment providing childbirth care in SUS. While São Paulo State has 1.1 obstetric nurses per establishment, the metropolitan Health Regions group's ratio is 2.8 . The high, medium, and low urbanization regions have $0.4,0.2$, and 0.3 obstetric nurses per health establishment, respectively.

With a smaller presence of medical professionals in less urbanized regions, there may also be a smaller supply of physicians who oppose the medicalized and interventionist care logic, limiting the possibility of selecting professionals working in these establishments in the regions. From the data referring to the number of obstetric nurses per health establishment, we can affirm that there is no direction in the care model that allows low-risk/usual risk childbirth care to be performed by non-medical professionals. This finding may also be related to the different sociocultural characteristics and care models adopted in different locations, which directly interfere in the professionals' and women's choice of what type of 
childbirth since the maternal and fetal health pathological conditions do not show substantial differences worldwide, as suggested by Patha and Malik. ${ }^{8}$

The necessity of Brazilian studies that seek to deepen the understanding of childbirth care role model and the incorporation of the non-medical professional in the number of cesarean sections is evident. Brazil is known to have a highly medicalized obstetric care model with intensive use of technology and little participation by obstetric nurses and midwives. ${ }^{8}$ Childbirth care model is not centered on the physician and shows to be well established in some countries. For example, in the Netherlands, only $44.9 \%$ of the births are assisted by physicians with assisted concentration on elective cesarean sections, babies in non-cephalic presentation, multiple pregnancies, preterm deliveries, postcesarean deliveries, and induced labor. 19 Peru has a massive inclusion of midwives, who serve $70.3 \%$ of the women in G1 and $81.9 \%$ of the women in G3 The observed cesarean section rate was $17.0 \%$ and $6.68 \%$ in these groups, respectively. 21 The percentage of women assisted by obstetric nurses or obstetricians is unknown in Brazil since Sinasc does not provide such information.

Besides the care model, one of the possible explanations for the alarming cesarean rates observed in this study refers to the Brazilian medical training. A qualitative study by Nakano et al.,22 which analyzed interviews with opinion-forming obstetricians (professors, speakers, editors of specialized journals, and authors of articles and books), identified that cesarean section is seen as a usual way of being born, a safe surgery, which provides greater control over birth and protects from the risks of other interventions. The authors point out that the cesarean section has become a constituent part of the obstetrician's identity, which differentiates it from the care provided by other professionals qualified to monitor physiological births. ${ }^{22}$

We can affirm that two childbirth care models coexist in Brazil. The first refers to a private model, where women are attended by physicians of choice, with the possibility of performing prenatal care and childbirth with the same professional. The other is a public care model assured by SUS, in which women are assisted during prenatal care by professionals who will not perform their childbirth care. These women are referred to an obstetric emergency service, where they will be assisted by professionals on duty, mostly physicians. These professionals have no bonds with patients, and their wages do not depend on the birth route. SUS childbirth care model is similar to the European model, which had a cesarean rate of $25 \%$ in 2016.23 However, even with a similar care model, Brazil displays alarming cesarean section rate in public establishments and, as revealed in this study, the rate was $50.5 \%$ in São Paulo State. Both public and nonprofit establishments analyzed in this study have a care model where women are assisted at birth by professionals on duty, but the outcome of the birth route differs by the type of administration and location of the establishments.

Some limitations of this study must be mentioned. First, it was not possible to breakdown births in establishments managed by nonprofit entities by funding source (SUS or private/health insurance) since the Sinasc database does not provide this type of information, only the place of birth. Therefore, the cesarean section rate of these establishments may have the bias of also accounting for births financed by the health insurance or private individuals, which, as is known, mostly perform cesarean surgeries. Another limitation is because the live births monitoring panel, according to epidemiological risk classification (Robson's Groups), does not subdivide Groups 2 (nulliparous) and 4 (multiparous without previous cesarean section) to identify elective cesareans and labor-induced cesarean sections. Therefore, elective cesarean sections, an issue of great concern for women and babies' health, could not be accounted for and discussed. Finally, as already mentioned in a previous study, the potential misclassification of some women who were admitted to the service under spontaneous labor is observed, but oxytocin was used to induce the labor. Therefore, they would belong to groups 1 and 3, but they could have been wrongly classified in groups 2 and 4.13

This study highlights the importance of investigating regional differences in the organization of childbirth care and understanding the scope of public policies in these different realities. It shows the heterogeneity of childbirth care in SUS in Saõ Paulo State, despite existing guidelines that should be followed by all the cities. It is noteworthy the different cesarean section rates when analyzing the different conditions in the regional urbanization and how establishments are managed. The less urbanized regions presented showed cesarean section rates significantly higher than the metropolitan and high urbanization regions. When considering the establishment administration, we noticed that the public establishments of the cesarean section rates were significantly lower than the nonprofit entities' rates. This difference was maintained in the metropolitan regions, but the cesarean section rates between the two types of administration were similar to the less 
urbanized regions observed. Further studies are required to understand the behavior of cesarean section rates in the public and nonprofit establishments in São Paulo State, especially in low urbanized regions. It is not possible to state the reason for these regional differences. However, the data point to the fact that, while having fewer physicians available, the less urbanized regions do not have non-medical professionals to perform childbirth care. That is, the lower the availability of physicians does not alter the centrality of care in the biomedical model. For a better understanding of this reality, new research is necessary so that the care model, the profile, the availability of professionals, and local policies to reduce cesarean rates. The results of this study contribute to the understanding of the

\section{References}

1. Betrán AP, Ye J, Moller AB, Zhang J, Gülmezoglu AM, Torloni MR. The increasing trend in caesarean section rates: global, regional and national estimates: 1990-2014. PloSone. 2016; 11 (2): e0148343.

2. Brasil. Ministério da Saúde. Secretaria de Vigilância em Saúde. Departamento de Vigilância de Doenças e Agravos Não Transmissíveis e Promoção da Saúde. Saúde Brasil 2014: uma análise da situação de saúde e das causas externas / Ministério da Saúde, Secretaria de Vigilância em Saúde, Departamento de Vigilância de Doenças e Agravos Não Transmissíveis e Promoção da Saúde. Brasília, DF; 2015.

3. Secretaria de Estado da Saúde de São Paulo. Plano estadual de saúde - PES: 2016-2019. São Paulo: Secretaria de Estado da Saúde de São Paulo; 2015.

4. Diniz CS, Niy DY, Andrezzo HF, Carvalho PC, Salgado HD. A vagina-escola: seminário interdisciplinar sobre violência contra a mulher no ensino das profissões de saúde. Interface Comun Saúde Educ. 2016; 20: 253-9.

5. Brasil. Ministério da Saúde. Banco de dados do Sistema Único de Saúde - DATASUS. [acesso 25 fev 2019]. Disponível em: http://www.datasus.gov.br

6. OMS (Organização Mundial da Saúde). Declaração da OMS sobre taxas de cesáreas. Genebra; 2014.

7. WHO (World Health Organization). Robson classification: Implementation manual. Geneva; 2017.

8. Patah LE, Malik AM. Modelos de assistência ao parto e taxa de cesárea em diferentes países. Rev Saúde Pública. 2011; 45 (1): 185-94.

9. Albuquerque MV, Viana AL, Lima LD, Ferreira MP, Fusaro ER, Iozzi FL. Desigualdades regionais na saúde: mudanças observadas no Brasil de 2000 a 2016. Ciênc Saúde Coletiva. 2017; 22 : 1055-64.

10. IBGE (Instituto Brasileiro de Geografia e Estatística). Regiões de influência das cidades - Regic/2007. Rio de Janeiro; 2008. complexity related to the high cesarean section rates in São Paulo State and that the different regional realities in São Paulo territory should be taken into consideration by health policies that aim to reduce cesarean sections' rates.

\section{Authors' contribution}

Lucena FS and Duarte LS participated in the conception and elaboration of the study and interpretation of the results. Garcia MT participated in the conception and elaboration of the study, data analysis, and interpretation of the results. All authors approved the final version of the manuscript.

11. Duarte LS. Desenvolvimento desigual e a regionalização do SUS: uma análise territorial dos recursos financeiros para as redes de atenção à saúde no Estado de São Paulo (2009-2014) [Tese]. São Paulo: Faculdade de Saúde Pública da Universidade de São Paulo; 2016.

12. EMPLASA. Rede urbana e regionalização do Estado de São Paulo. São Paulo: EMPLASA; 2011.

13. Nakamura-Pereira M, do Carmo Leal M, Esteves-Pereira AP, Domingues RM, Torres JA, Dias MA, Moreira ME. Use of Robson classification to assess cesarean section rate in Brazil: the role of source of payment for childbirth. Reprod Health. 2016; 13 (3): 128.

14. Zaiden L, Nakamura-Pereira M, Gomes MAM, EstevesPereira AP, Leal MC. Influência das características hospitalares na realização de cesárea eletiva na Região Sudeste do Brasil. Cad Saúde Pública. 2020; 36 (1): e00218218.

15. Alonso BD, Silva FM, Latorre MD, Diniz CS, Bick D. Caesarean birth rates in public and privately funded hospitals: a cross-sectional study. Rev Saúde Pública. 2017; 51: 101

16. Zhang JW, Branch W, Hoffman M, De Jonge A, Li SH, Troendle J, Zhang J. In which groups of pregnant women can the caesarean delivery rate likely be reduced safely in the USA? A multicentre cross-sectional study. BMJ Open. 2018; 8(8): e021670.

17. Dias MA, Domingues RM, Schilithz AO, NakamuraPereira M, Leal MC. Factors associated with cesarean delivery during labor in primiparous women assisted in the Brazilian Public Health System: data from a National Survey. Reprod Health. 2016; 13 (3): 114.

18. Aguirre R, Antón JI, Triunfo P. Análisis de las cesáreas em Uruguay por tipo de centro hospitalario. Gac Sanit. 2018; pii: S0213-9111(18)30045-1.

19. Zhang J, Geerts C, Hukkelhoven C, Offerhaus P, Zwart J, de JongeA. Caesarean section rates in subgroups of women and perinatal outcomes. BJOG. 2016; 123 (5): 754-61. 
20. Oliveira RR, Melo EC, Novaes ES, Ferracioli PLRV, Mathias TAF. Factors associated to caesarean delivery in public and private health care systems. Rev Esc Enferm USP. 2016; 50 (5): 733-40.

21. Tapia V, Betran AP, Gonzales GF. Caesarean section in Peru: analysis of trends using the Robson Classification System. PloSone. 2016; 11 (2): e0148138.
22. Nakano AR, Bonan C, Teixeira LA. O trabalho de parto do obstetra: estilo de pensamento e normalização do "parto cesáreo" entre obstetras. Physis: Rev Saúde Coletiva. 2017; 27: 415-32.

23. Batista-Filho M, Rissin A. A OMS e a epidemia de cesarianas. Rev Bras Saúde Mater Infant. 2018; 18 (1): 5-6.

Received on July 15, 2019

Final version presented on June 25, 2020

Approved on August 24, 2020 